\title{
The femtochemistry of the ferrioxalate actinometer
}

\author{
Steffen Straub, Paul Brünker, Jörg Lindner, and Peter Vöhringer ${ }^{*}$ \\ Chair of Molecular Physical Chemistry, Institute for Physical and Theoretical Chemistry, University \\ of Bonn, Wegelerstraße 12, 53115 Bonn, Germany
}

\begin{abstract}
The ferrioxalate actinometer is widely used as an analytical standard to determine the photon flux of light sources in photochemical reactors. Yet, the underlying mechanistic functioning of the actinometer at the molecular level is entirely unknown. Here, we present results from femtosecond UV-pump/mid-infrared-probe spectroscopy to reveal the elementary events including the primary $\mathrm{C}-\mathrm{C}$ and $\mathrm{Fe}-\mathrm{O}$-bond breakages that follow an initial photon absorption by the ferrioxalate complex.
\end{abstract}

\section{Introduction}

The photochemistry of aqueous transition metal dicarboxylates often involves the formation of reactive oxygen species through Fenton-type redox chemistry and plays an important role in the degradation of dissolved organic matter in natural waters. Moreover, a solution of ferrioxalate (i.e. potassium trisoxalatoferrate(III), $\left[\mathrm{Fe}^{\mathrm{III}}\left(\mathrm{C}_{2} \mathrm{O}_{4}\right)\right]^{3-}$, cf. Fig. 1, for its molecular structure) in water serves in the photochemistry community as a calibration system that allows for the accurate in-situ determination of radiative fluxes emitted by light sources of photochemical reactors. Despite being endorsed by the International Union for Pure and Applied Chemistry for applications in liquid-phase actinometry [1] the molecularlevel working principle of the ferrioxalate actinometer remains largely a mystery.
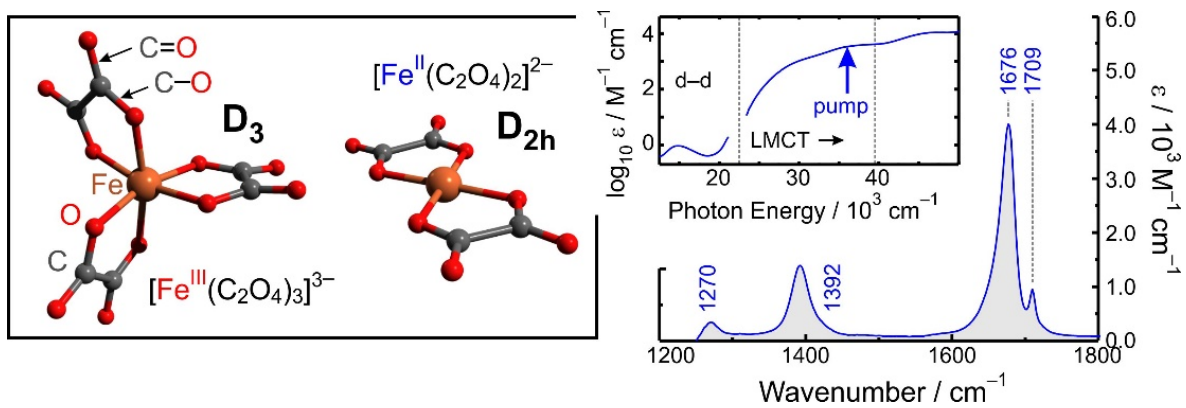

Fig. 1. Left: Optimized molecular structure of the ferrioxalate parent and the ferrooxalate product complex, both from a DFT calculation (B3LYP/def2-TZVP/CPCM(water)). Right: FTIR spectrum and $\mathrm{UV} / \mathrm{Vis}$-spectrum (inset) of aqueous ferrioxalate solutions.

* Corresponding author: p.voehringer@uni-bonn.de 
The actinometer relies on the effective radiative conversion of ferric (i.e. $\mathrm{Fe}^{\mathrm{III}}$ ) to ferrous $\left(\mathrm{Fe}^{\mathrm{II}}\right)$ forms of oxalates according to, $2\left[\mathrm{Fe}^{\mathrm{III}}\left(\mathrm{C}_{2} \mathrm{O}_{4}\right)_{3}\right]^{3-}+\mathrm{h} v \rightarrow 2\left[\mathrm{Fe}^{\mathrm{II}}\left(\mathrm{C}_{2} \mathrm{O}_{4}\right)_{2}\right]^{2-}+$ $2 \mathrm{CO}_{2}+\mathrm{C}_{2} \mathrm{O}_{4}^{2-}$ (see Fig. 1 for the structure of the product). The conversion of more than one equivalent of ferrioxalate by a single photon is usually rationalized by the HatchardParker mechanism [2], which consists of an inner sphere electron transfer on the optically prepared excited state surface, * $\left[\mathrm{Fe}^{\mathrm{III}}\left(\mathrm{C}_{2} \mathrm{O}_{4}\right)_{3}\right]^{3-} \rightarrow\left[\mathrm{Fe}^{\mathrm{II}}\left(\mathrm{C}_{2} \mathrm{O}_{4}\right)_{2}\right]^{2-}+\mathrm{C}_{2} \mathrm{O}_{4}{ }^{\bullet-}$, followed by a bimolecular, outer sphere electron transfer from the oxalate radical anion product to another ferrioxalate ground-state complex in the bulk solution, $\mathrm{C}_{2} \mathrm{O}_{4}{ }^{\bullet-}+\left[\mathrm{Fe}^{\mathrm{III}}\left(\mathrm{C}_{2} \mathrm{O}_{4}\right)_{3}\right]^{3-} \rightarrow$ $\left[\mathrm{Fe}^{\mathrm{II}}\left(\mathrm{C}_{2} \mathrm{O}_{4}\right)_{2}\right]^{2-}+2 \quad \mathrm{CO}_{2}+\mathrm{C}_{2} \mathrm{O}_{4}{ }^{2-}$. However, despite many efforts from time-resolved spectroscopy [3] including state-of-the-art X-ray absorption [4, 5], it remains totally unclear (i) on what time scale the initial ligand loss occurs and (ii) whether or not the formation of the carbonaceous radical anion requires a prior electron transfer from the oxalate ligand to the metal center. To clarify these issues, we have performed femtosecond pump/probe spectroscopy on aqueous solutions of ferrioxalate using 266-nm excitation pulses (corresponding to ligand-to-metal charge transfer (LMCT) excitation of the complex, cf. Fig. 1, inset) and tunable mid-infrared (MIR) probe pulses for monitoring structural changes associated with the ligand sphere surrounding the iron center.

\section{Results and Discussion}

Fig. 1 (right panel) shows the linear MIR spectrum of aqueous ferrioxalate and zooms into the $\mathrm{C}-\mathrm{O}$ and $\mathrm{C}=\mathrm{O}$ stretching region of the oxalate ligands. Of particular relevance to this work is the most intense band at $1676 \mathrm{~cm}^{-1}$, which can be assigned mostly to the doubly degenerate $\mathrm{C}=\mathrm{O}$ stretches having E-symmetry. The minor peak at $1709 \mathrm{~cm}^{-1}$ must be attributed to the totally symmetric $\mathrm{C}=\mathrm{O}$ stretch (species $\mathrm{A}_{1}$ ), which obtains detectable infrared transition strength from of a symmetry lowering of the complex induced through its interactions with the counter-ion and the water solvent.

A pump-probe spectrum in the oxalate stretching region is displayed in Fig. 2a. Both, ground-state bleach (blue bands) and induced absorptions (red) bands are detected. Removing the former contribution by adding a suitably weighted FTIR spectrum of the sample to the raw data provides purely absorptive product (paP) spectra as exemplified in Fig. $2 \mathrm{~b}$ for a very short and a very long delay. The early paP-spectrum indicates that after $500 \mathrm{fs}$, a vibrationally excited $\mathrm{CO}_{2}$-molecule is expelled from the ligand sphere as evidenced by a broad signal around $2300 \mathrm{~cm}^{-1}$, i.e. where the asymmetric stretch of aqueous $\mathrm{CO}_{2}$ is expected to absorb. Thus, the residual absorptions in the oxalate $\mathrm{C}-\mathrm{O}$ and $\mathrm{C}=\mathrm{O}$ regions can be assigned to an iron-containing intermediate. Electronic structure calculations show that this spectrum is indicative of a ferrous dioxalatoiron(II) carbon dioxide complex whose structure is displayed in Fig. 2c. The ground-state bleach recovery (cf. Fig 2 d) demonstrates that $\sim 23 \%$ of the initially excited parent complexes undergo ultrafast internal conversion within less than $3 \mathrm{ps}$. Thus, the primary yield for this dissociation reaction amounts to $77 \%$ as confirmed by the amplitude of the $\mathrm{CO}_{2}$-absorption at its fundamental frequency $\left(2341 \mathrm{~cm}^{-1}\right.$, cf. Fig. $2 \mathrm{~b}$, green spectrum, upper right) and at a very long delay (50 ps). Moreover, kinetic traces recorded in the $\mathrm{CO}_{2}$-stretching region (see Fig. 2e) reveal that vibrational relaxation of the carbonaceous fragment occurs on the time scale of about $10 \mathrm{ps}$ in a mode-specific fashion.

The entire spectro-temporal evolution in the mid-infrared region can be rationalized as follows. Following LMCT-excitation, the excited state of the parent complex dissociates within $500 \mathrm{fs}$. Both, $\mathrm{C}-\mathrm{C}$ and $\mathrm{Fe}-\mathrm{O}$ bond breakages, which are required for the $\mathrm{CO}_{2}-$ release, compete with internal conversion. The non-adiabatic transition takes place with a time constant of $1.4 \mathrm{ps}$, thereby explaining the primary quantum yield for $\mathrm{CO}_{2}$-formation of 
$77 \%$. The parent ground state is formed vibrationally hot and the intramolecular redistribution of the excess energy occurs with 2.5 ps as evidenced by a spectral shifting of the hot ground-state absorption (data not shown). Moreover, the ferrous intermediate is also born in a vibrationally excited fashion. Here, the excess energy drives a structural reorganization of the penta-coordinated species that gives rise to an upshift of its absorption from $1641 \mathrm{~cm}^{-1}$, to $1635 \mathrm{~cm}^{-1}$. The final products of this structural rearrangement are the planar ferrous dioxalate of the actinometer's net reaction and a free carbon dioxide radical anion. The latter species absorbs at $1660 \mathrm{~cm}^{-1}$ and its absorption is clearly discernible in the paP-spectrum after $1 \mathrm{~ns}$.
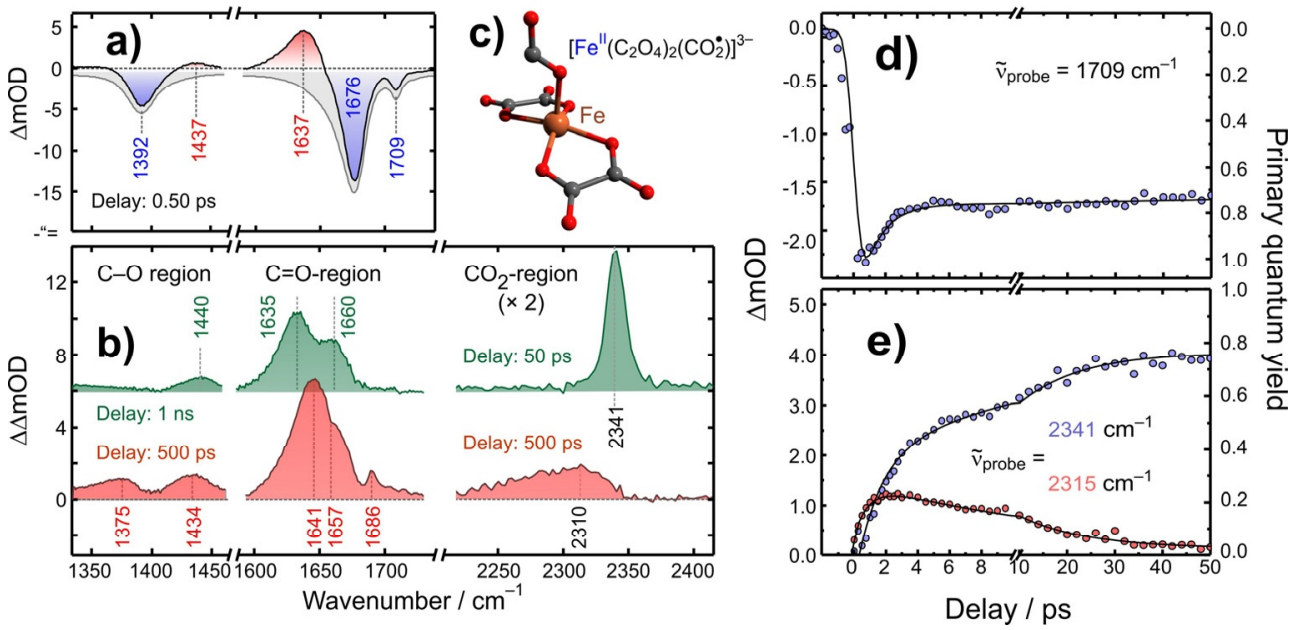

Fig. 2. a) fs-UV-pump/MIR-probe spectrum of aqueous ferrioxalate at a delay of $500 \mathrm{fs}$. b) paPspectra for a very short (red) and a very long delay (green). c) Structure of the penta-coordinated intermediate. d) Time-resolved ground-state beach recovery. e) Time-resolved rise of the $\mathrm{CO}_{2}$ absorption at two different probe frequencies.

The ferrous intermediate exhibits an intriguing electronic structure that can be described by the structural motif, $\mathrm{Fe}^{\mathrm{II}}-\mathrm{O}-\mathrm{C}^{\bullet}=\mathrm{O}$, indicating a carbon dioxide radical anion ligand $(\mathrm{S}=1 / 2)$ that is bound and ferromagnetically coupled to a high-spin iron(II) center $(\mathrm{S}=2)$ thereby giving rise to a total sextet multiplicity $(\mathrm{S}=5 / 2)$. Because significant spin density resides on the OCO-ligand, this intermediate promises interesting carbon and oxygencentered chemical reactivity, which we will explore in the near future. In summary, we have used ultrafast UV-pump/MIR-probe spectroscopy to disclose the elementary lightinduced primary elementary processes of aqueous ferrioxalate. The photochemical mechanism presented here finally provides the long-sought molecular-level picture of the inner workings of the ferrioxalate actinometric standard.

Financial support by the German Science Foundation, grant VO 593/7-1, is gratefully acknowledged.

\section{References}

1. H. J. Kuhn, S. E. Braslavsky, R. Schmidt, Pure \& Appl. Chem. 76, 2105 (2004)

2. C.A. Parker, C.G. Hatchard,, J. Phys. Chem. 63, 22 (1959)

3. J. Chen, H. Zhang, I.V. Tomov, M. Wolfsberg, X.L. Ding, P.M. Rentzepis, J. Phys. Chem. A 113, 8820 (2009)

4. Y. Ogi et al. Struct. Dyn. 2, 034901 (2015); G.C. O’Neil et al. J. Phys. Chem. Lett. 8, 1099 (2017) 